Estudios Públicos 165 (2022), I77-184

DOI: https://doi.org/10.38178/07/83089//3|4210927

Reseñ a

David Carr. Historical Experience. Essays on the Phenomenology of History. London, New York: Routledge, 202 I. US\$I 5 I.97 (ISBN: 978036734927 I), I 76 pP.

\title{
Miguel Valderrama
}

Universidad Diego Portales, Chile

$\mathrm{T}$ ras la muerte del filósofo estadounidense Hayden White, en marzo del año 2018, circuló con insistencia la pregunta de si una época de la filosofía de la historia había llegado a su término, al menos de aquella identificada con el narrativismo. Y, en efecto, en el ámbito de la filosofía de la historia angloamericana, la controvertida figura de Hayden White pareció dominar sin contrapesos la disciplina por cerca de cincuenta años. Desde la publicación de Metahistory (1973) hasta The Practical Past (2014), la investigación whiteana se impuso ampliamente en las discusiones filosóficas sobre la figuración histórica o sobre la naturaleza del pasado. De un modo más preciso, podría advertirse que la perspectiva analítica de la filosofía de la historia, que durante las décadas de 1950 y 1960 estuvo dominada por preocupaciones de orden epistemológico, se vio conmovida de un modo radical tras la publicación de Metahistory. El desplazamiento de perspectiva en el análisis de la narración histórica, que abandona la pregunta por la identificación de las estructuras atómicas de significación del lenguaje para centrar el examen en lo que Frank Ankersmit (2012) identificó como la 'sustancia narrativa' del texto histórico, situó en el centro de la discusión teórica y filosófica el problema de la figuración en el discurso historiográfico.

Sin embargo, y a pesar de los esfuerzos sostenidos de Hayden White por desplazar la problemática epistemológica y ontológica del análisis histórico, habría que advertir que las discusiones contemporáneas en

Miguel ValderRama es Licenciado en Historia y Doctor en Filosofía de la Universidad de Chile. Es Investigador Adjunto del Instituto de Filosofía, Universidad Diego Portales, Chile. Dirección: Ejército 260, Santiago Centro, Santiago, Chile, CP 8370056. Email: miguelvalderramac@hotmail.com. 
torno al denominado 'narrativismo' persisten en retornar a un análisis epistemológico de la representación histórica. Así, la cuestión de cómo los relatos del mundo y en especial del ya ausente mundo del pasado, pueden ser 'verdaderos', 'representativos' o 'auténticos', se impone sobre aquella otra que se interroga en último término por el lugar de la figuración en la escritura de la historia. Esta discusión en torno a los límites y posibilidades de la representación histórica reintroduce de un modo renovado problemas y preguntas propias de la epistemología, una disciplina que desde los análisis de Quine, Davidson o Rorty se creía perimida. En otras palabras, el retorno de la epistemología en los recientes análisis del narrativismo activa por otros medios una indagación que busca correlacionar 'estados del mundo' con 'descripciones de estados del mundo'. En términos más afines a la reformulación que Kalle Pihlainen (2017) ofrece del problema en el ámbito de la filosofía de la historia, se podría afirmar que la proposición correlacionista que interroga sobre si las estructuras de significación de la narración histórica se corresponden realmente con las estructuras de significación que se encuentran en la realidad, sigue siendo la preocupación dominante en las discusiones actuales del narrativismo. Esta indagatoria, que en términos generales constituye el programa básico de la epistemología y que inquiere sobre qué tipo de enunciados verdaderos se encuentran en relación representacional con elementos no lingüísticos, introduce en la discusión narrativista cuestiones propias del debate antirrepresentacionalista de fines del siglo pasado. Y, más ampliamente, reconduce la escena narrativista contemporánea a un momento 'postextual' o 'pos-posmoderno' del narrativismo (Partner 2009) que encuentra puntos de contacto con el giro ontológico en curso, descrito en filosofías como las de Graham Harman, Quentin Meillassoux, Markus Gabriel o Maurizio Ferraris.

De un modo que parece intersectar esta breve descripción del panorama de disputas teórico-filosóficas en torno a la historia, a la escritura de la historia y al conocimiento histórico, el nombre de David Carr (1940-) se presenta como contraseña de una orientación continental de la filosofía de la historia angloamericana que tiene en la fenomenología su referencia primera y principal. Esta referencia no solo se limita a continuar en territorio estadounidense una tradición de pensamiento que en el ámbito europeo se identifica con Edmund Husserl, Martin Heidegger, Maurice Merleau-Ponty o Paul Ricoeur, sino que además parece 
condensar los esfuerzos de la fenomenología en el ámbito de la teoría y la filosofía de la historia orientados a salvaguardar un concepto de experiencia capaz de rehabilitar un proyecto historiográfico de pretensiones científicas. En efecto, se puede señalar que tras la publicación en History and Theory de 'Narrative and the Real World: An Argument for Continuity' (1986a), la posición de Carr se ha presentado en el orden de las discusiones estadounidenses como un sólido alegato contra el narrativismo, contra la discontinuidad que necesariamente este presupondría entre narración y realidad. A la vez, se ha visto en la descripción que el filósofo ofrece de la narración una ajustada descripción de lo que se pone en juego en la querella en torno al narrativismo:

Si el papel de la narración consiste en introducir algo nuevo en el mundo, y lo que introduce es la síntesis de lo heterogéneo, entonces la narración añade a los hechos del mundo una forma que de otra manera no tienen. Un relato redescribe el mundo, lo describe como si fuera lo que, presumiblemente, no es. (Carr 1986a, 120)

Oponiéndose a la afirmación de Louis O. Mink (1987, 60), que observa que "las historias no son vividas, sino contadas", Carr se esfuerza en reconocer la continuidad que existiría entre la narración y la acción humana. Esta continuidad se encontraría en el parentesco que el filósofo advierte entre la estructura de medios-y-fines de la acción y la estructura de principio-medio-fin de la narrativa. Según Carr,

\footnotetext{
la narrativa no es solo una exitosa forma posible de describir hechos, su estructura se inserta en los hechos mismos. Lejos de ser una distorsión formal de los hechos que relata, una explicación narrativa es la prolongación de sus rasgos fundamentales. Mientras otros discuten a favor de la discontinuidad radical entre narrativa y realidad, yo no solo sostendré que hay continuidad sino una comunidad formal. (Carr 1986a, 117)
}

Esta continuidad entre narrativa y realidad tiene en la experiencia su principio de unidad y homogeneidad, principio mínimo y máximo del que se deduce una comprensión del mundo de naturaleza histórica organizada a partir del despliegue de una acción humana de raíz intencional, que se vuelve autoevidente a través de la narración. La configuración de la acción humana es teleológica, la estructura de medios-y-fines de la acción se acopla o corresponde con la estructura de principio-medio-fin de las historias que narran la aprehensión de un determinado sentido del mundo. "Las historias son contadas en tanto vividas, y vividas en tanto contadas" (Carr 1986a, 126). 
Después de 'Narrative and the Real World' (1986a), Carr ha ido elaborando pacientemente una aproximación fenomenológica a conceptos fundamentales del quehacer historiográfico. Cierto es que esta aproximación puede ya rastrearse en su temprana monografía sobre Husserl y la historia, publicada en 1974, bajo el título Phenomenology and the Problem of History. A Study of Husserl's Trascendental Philosophy, o en la entrada dedicada al vocablo 'Historia' que redactó para la Encyclopedia of Phenomenology, aparecida en 1997, en el volumen 18 de las Contribuciones a la fenomenología auspiciadas por el Center for Advance Research in Phenomenology. No obstante, es solo con Time, Narrative, and History (1986b) y con Experience and History (2014) donde esta aproximación a la historia desde una perspectiva fenomenológica se despliega de un modo más original y sistemático. Esta originalidad -es el argumento que se quiere defender en esta reseña- se construye a partir de la fuerte oposición que Carr despliega contra las tesis narrativistas representadas fundamentalmente por las posiciones de Mink y White (ver Ankersmit 2012, 37-40). Esta oposición convierte a David Carr en un contradictor silente del narrativismo, especie de mediador evanescente de una interpretación de la experiencia en la que se reconocen los rasgos que definen un modelo preestablecido de ciencia histórica ampliamente compartido, al mismo tiempo que se desestima - por las mismas razones - la originalidad de la empresa filosófica que sirve de sostén a dicha labor de reorganización de las relaciones entre experiencia e historia. En otras palabras, si puede reconocerse en Carr una orientación similar a la desarrollada por Frank Ankersmit en libros como History and Tropology (1994) o Sublime Historical Experience (2005) en vistas a elaborar una nueva teoría de la experiencia histórica, esta orientación no ha sido igualmente valorada por la crítica estadounidense. Prueba de ello es la ausencia de referencias a la obra de Carr en el estudio que Martin Jay (2005) dedicara a comienzos de la primera década del presente siglo a las variaciones americanas y europeas sobre el 'tema universal' de la experiencia.

Historical Experience. Essays on the Phenomenology of History, publicado por Routledge en el presente año, puede señalarse como el más reciente esfuerzo de Carr por defender la centralidad de la experiencia para la consciencia y el saber histórico. Dividido en tres grandes secciones, cada una compuesta por cuatro ensayos, Historical Experience reúne trabajos previamente publicados entre los años 2006 y 2021. Historicity, 
Narrative, and Time, Teleology and History y Embodiment and Experience son los títulos de las secciones que organizan la presentación de los textos. Podría decirse que ese mismo orden de exposición es índice de la propia trayectoria intelectual del autor, en tanto el medio principal que ha encontrado Carr al momento de pensar la continuidad entre narración e historia es un concepto teleológico de acción encarnado en una experiencia corporal y colectiva. Para afirmar esta experiencia, en tanto experiencia histórica, Carr recurre a una idea de existencia humana fuertemente determinada por una poética de la narración que por momentos parece dar la impresión de buscar reintroducir la vieja pretensión del sujeto constituyente de dominar el sentido. En otros términos, la centralidad de la teleología al momento de afirmar el nexo inextricable entre experiencia y narración revela una estructura de significación de raíz universal que tiene como concepto principal a la acción intencional. Este concepto de acción aseguraría la continuidad entre las narrativas y el mundo real, en tanto la misma realidad se vería informada por un tipo de acción que se despliega según un sentido o finalidad que se vuelve autoconsciente a través del relato, de la narración.

Historical Experience reitera la tesis de la continuidad entre narración e historia, entre experiencia y representación. No hay ningún giro sorpresivo en la argumentación, no hay desplazamientos que prefiguren aportaciones nuevas a una perspectiva fenomenológica ya consolidada en ensayos anteriores sobre fenomenología de la historia.

Sin embargo, en la introducción a Historical Experience, el filósofo estadounidense no deja de advertir de entrada sobre la naturaleza inaudita de los acontecimientos que rodean la propia escritura del libro.

En el lenguaje actual —observa—, la pandemia del coronavirus y las protestas generalizadas contra la injusticia racial que se le superponen, se describen como acontecimientos de 'proporciones históricas'. A medida que vivimos estos acontecimientos, ¿cuál es la naturaleza de nuestra experiencia de ellos? (1)

La pregunta de Carr introduce el acontecimiento en la historia o, más precisamente, introduce la cuestión del acontecimiento y la narración histórica. Cuestión capital, cabeza de toda reflexión filosófica y teórica sobre la historia en el presente. Cuestión que vuelve sobre la experiencia histórica, pero que parece desbordarla precisamente ahí donde el acontecimiento nombra un 'punto de inflexión' (la expresión es 
de Carr), donde se muestra en una magnitud sin precedentes, sin antecedencia alguna capaz de incorporar su emergencia en una estructura de significación. A pesar de reconocer este desplazamiento en la noción de acontecimiento, de advertir su no contemporaneidad histórica, Carr desplaza su atención del acontecimiento a los procesos de enmarcamiento de las narrativas históricas, a los efectos de desnaturalización del llamado mundo histórico a que estos acontecimientos dan lugar. En este sentido, ve en acontecimientos como la pandemia o el calentamiento global índices justamente de 'acontecimientos históricos' en tanto 'acontecimientos vividos'. Las transformaciones profundas en las estructuras de la vida social, junto con la certeza de que la experiencia de esas transformaciones es individual a la vez que colectiva, lleva a Carr a observar que los acontecimientos históricos se viven en diferentes escalas temporales (individuales y colectivas), que implican una cierta dislocación de la temporalidad organizada a partir de una anticipación futura, y que suponen un 'punto de inflexión', una ruptura en el orden de significación en el que se traman las historias. ¿Obedece esta descripción del acontecimiento a la lógica de una fenomenología de la experiencia histórica? ¿Puede una fenomenología de la historia dar cuenta del acontecimiento? ¿Es posible historizar el acontecimiento, en todo lo que en él nombra un fin de mundo? En Historical Experience estas preguntas aparecen reformuladas en una reflexión sobre la experiencia histórica que se ofrece a modo de traducción de una reflexión sobre el acontecimiento. Este gesto traslaticio vuelve a reafirmar la continuidad entre narrativas y mundo real, y con ello vuelve a insistir en una noción de historia e historicidad que desde hace ya más de cincuenta años ha sido objeto de fuertes cuestionamientos por parte de tradiciones filosóficas y de pensamiento de signo diverso. La misma noción de poshistoria, que puede rastrearse en nombres tan heterogéneos como los de Hannah Arendt, Pier Paolo Pasolini o Peter Sloterdijk, sirve de testimonio del agotamiento del concepto moderno de historia que está en la raíz de la fenomenología de Carr.

En efecto, no solo ningún ensayo se dedica a la cuestión del acontecimiento en el libro de Carr, sino que, además, pese a advertir la emergencia de acontecimientos sin medida común en el mundo histórico, se insiste en una indagación fenomenológica que busca delinear la noción de experiencia histórica a través de los efectos de conmoción que la emergencia del acontecimiento provocaría sobre los marcos narrativos 
que sostienen las interpretaciones del mundo histórico, como si el acontecimiento aún fuera un hecho sometido a descripción, según la clásica descripción ofrecida por Arthur Danto (1968). En el ámbito de disputas del narrativismo, las nociones de 'acontecimiento sublime', 'acontecimiento modernista' o 'experiencia histórica sublime' se presentan como ensayos conceptuales que buscan tomar nota de la transformación de la noción de acontecimiento en un mundo poshistórico. Este esfuerzo de conceptualización advierte que las estructuras temporales, en tanto estructuras de significación, ya no pueden sostenerse en la primacía de la subjetividad al momento de elaborar nociones tales como las de historia, experiencia histórica o historicidad. ¿Qué podría ser un pensamiento de la historia vaciado de la noción de sujeto como locus de enunciación narrativa? ¿Podría todavía hablarse de historia, de una experiencia histórica, después del fin de la historia? David Carr parece detenerse en el umbral de estas cuestiones, convencido de que todavía es posible vivir historias, es decir, contarlas en tanto vividas.

\section{Bibliografía}

Ankersmit, F. 1994. History and Tropology: The Rise and Fall of Metaphor. California: University of California Press.

Ankersmit, F. 2005. Sublime Historical Experience. Stanford: Stanford University Press.

Ankersmit, F. 2012. Meaning, Truth, and Reference in Historical Representation. Ithaca: Cornell University Press.

Carr, D. 1974. Phenomenology and the Problem of History. A Study of Husserl's Trascendental Philosophy. Evanston: Northwestern University Press.

Carr, D. 1986a. Narrative and the Real World: An Argument for Continuity. History and Theory 25(2), 117-131.

Carr, D. 1986b. Time, Narrative, and History. Bloomington: Indiana University Press.

Carr, D. 1997. History (312-314). En Embre, L. y Mohanty, J.N. (eds.), Encyclopedia of Phenomenology. New York: Springer-Science+Dusiness Media.

Carr, D. 2014. Experience and History: Phenomenological Perspectives on the Historical World. Oxford: Oxford University Press.

Danto, A. 1968. Analytical Philosophy of History. Cambridge: Cambridge University Press.

Jay, M. 2005. Songs of Experience. Modern American and European Variations on a Universal Theme. California: University of California.

Mink, L. 1987. Historical Understanding. Ithaca: Cornell University Press.

Partner, N. 2009. Narrative Persistence: The Post-Postmodern Life of Narrative Theory (81-104). En Ankersmit, F., Domanska, E. y Keller, H. (eds.), Re-figuring Hayden White. Stanford: Stanford University Press.

Pihlainen, K. 2017. The Work of History. Constructivism and a Politics of the Past. London: Routledge. 
White, A. 1973. Metahistory. The Historical Imagination in Nineteenth Century Europe. Baltimore: Johns Hopkins University Press.

White, A. 2014. The Practical Past. Evanston: Northwestern University Press. EP 